\title{
Craniofacial Morphometry for Craniofacial Implant
}

\author{
Morfometría Craneofacial para Implante Craneofacial
}

\author{
"Sergio Olate; **Paulo Hemerson de Moraes; ${ }^{* * *}$ Paulo Henrique Ferreira Caria; \\ ${ }^{* * * * *}$ Henrique Duque de Miranda Chaves Netto \& ${ }^{* * * * *}$ José Ricardo de Albergaria Barbosa
}

OLATE, S.; DE MORAES, P. H.; CARIA, P. H. F.; NETTO, H. D. M. C. \& BARBOSA, J. R. A. Craniofacial morphometry for craniofacial implant. Int. J. Morphol., 30(3):1166-1172, 2012.

SUMMARY: Craniofacial implants are being increasingly used to treat patients with sequelae of oncological resections, trauma, and congenital deficiencies, among other issues. The aim of this investigation was to establish the minimum and maximum bone dimensions present in the most used places for the insertion of craniofacial implants. A descriptive study was designed analyzing 40 human skulls using cone-beam computed tomography; in the volumetric reconstruction the points most often used in clinical investigations for the insertion of implants were selected, representing the orbital, perinasal, zygomatic bone and periauricular regions, measuring the distance between the cortical bones on the sagittal, axial and coronal planes; comparisons between gender and with other investigations with a similar aim were also made. In the supraorbital area, values of $7.92 \pm 1.82 \mathrm{~mm}$ were found and in the lateral area values of $7.54 \pm 0.98 \mathrm{~mm}$, allowing the placement of implants 5 or $6 \mathrm{~mm}$ in length. In the area of the zygomatic bone, dimensions of $10.4 \pm 2.35 \mathrm{~mm}$ were obtained, allowing the placement of implants $8 \mathrm{~mm}$ in length. In the periauricular area values were obtained of $2.93 \pm 0.55 \mathrm{~mm}$ in the superior region and $3.1 \pm 0.7 \mathrm{~mm}$ in the inferior region, whereas in the perinasal area implants $4 \mathrm{~mm}$ in length can be placed. We concluded that the craniomaxillofacial bone structure presents acceptable widths for the installation of implants; the periauricular region presents lower dimensions, with the possibility of intracranial communication in areas above the external auditory meatus.

KEY WORDS: Craniofacial implants; Bone morphometry; Extra-oral implant.

\section{INTRODUCTION}

After performing the first experiments with the "bone anchored hearing aid" (BAHA) systems in the temporal bone (Tjellström et al., 1981), the installation of extra-oral craniofacial implants for the retention of facial epithesis was recognized as a successful treatment (Tjellström, 1985; Tjellström et al., 1085).

Indicating the use of craniofacial implants has been defined for several pathological situations (Wolfaardt et al., 2003), including the sequelae of cancer, facial trauma, facial alterations due to malformations, among others, and that these often compete favorably with graft-based surgical reconstructions (Leonardi et al., 2008). Among the advantages of this technique are a relatively fast and friendly surgical sequence, the easy adaptation of the epithesis, low financial cost and an acceptable cosmetic standard depending on the location and extent of the defect (Miles et al., 2006).
The points for craniofacial implant placement have been identified in the region of the temporal bone, and orbital and perinasal structures, places where there may be significant limitations in terms of the amount and quality of bone. Jensen et al. (1992) conducted a morphometric study where areas with different widths were observed, presenting some areas of limited bone availability for the installation of these devices; however, this work was performed on 15 skulls of Hindu origin using a manual vernier caliper without identifying gender, age or cranial dentition features. Matsuura et al. (2002) studied 30 skulls of Japanese origin, taking sagittal sections in the periorbital, periauricular, perinasal and maxillaryregions and measurements with a digital vernier caliper, thereby demonstrating areas of reduced width, particularly in the temporal bone, as well as significant differences with the study by Jensen et al. For other hand, a previous paper showed a preliminary result of

* Assistant Professor, Division of Oral and Maxillofacial Surgery, Faculty of Dentistry, Universidad de La Frontera, Temuco, Chile.

** PhD. Student, Division of Oral and Maxillofacial surgery, Piracicaba Dental School, State University of Campinas, Campinas, Brazil.

*** Professor, Department of Morphology, Piracicaba Dental School, State University of Campinas, Campinas, Brazil.

***** Assistant Professor, Division of Oral and Maxillofacial Surgery, Medicine School, Universidade Federal de Juiz de Fora, Juiz de Fora, Brazil.

****** Professor, Division of Oral and Maxillofacial surgery, Piracicaba Dental School, State University of Campinas, Campinas, Brazil. 
this research (Olate et al., 2011), being one of the first researches using cone beam computed tomography for craniofacial implants analysis.

The aim of this investigation was to establish quantitatively the bone width available for the safe installation of extra-oral implants using cone beam computed tomography (CBCT).

\section{MATERIAL AND METHOD}

Forty human skulls from the Laboratory of Human Anatomy of the Department of Morphology in the Faculty of Dentistry at the State University of Campinas, Brazil were selected for this investigation. The samples were selected by an anatomist experienced in their state of preservation, defining an approximated age of 20 to 60 years. This study was approved by the ethic committee of the FOP-UNICAMP under file number 038/2010.

Study of image and measurement. Each skull was identified by a sequential Arabic number and positioned on a support that came in contact with the bilateral mastoid processes and the posterior part of the maxilla. Once the skull was centered, the CT examinations were performed with Cone Bean Computed Tomography (i-CATTM, 12bit, Imaging Sciences International, Hatfield, PA) with the following scan parameters: scan time, $40 \mathrm{~s} ; 120 \mathrm{kV}$; 3-8 $\mathrm{mA}$; field of view mode $13 \mathrm{~cm}$; voxel- $0,25 \mathrm{~mm}$. The resulting slice image data were converted to $3 \mathrm{D} C \mathrm{CT}$ images in DICON format, reconstructed using XoranCat software (version 3.1.62) and imported for analysis in iCATVision TM.2008 version 1.8.1.10. The reconstructed image was 2 $\mathrm{mm}$ (slice thickness) and cross-sectional CT images were obtained.

In the volumetric reconstruction the image was analyzed (Fig. 1), establishing the measurements of the anatomical points defined in the sagittal, axial and coronal sections (in the case of the region of the temporal bone), which were taken by visualizing the direction of the installation of the implant. The measurement was taken on two separate occasions by two different investigators with one week between each measurement; from these values an average was obtained that was used as the final value of the anatomical point. The start and end points of the measurement were taken between the proximal and distal cortical bones.

Anatomical landmark analyzed. Based on the morphometric investigations by Jensen et al. and Matsuura et al. and the researches by Wolfaardt et al., Tjellström and Tjellström et al. (1985), the anatomical sectors most often used for the installation of craniofacial implants selected from the volumetric reconstruction of the analyzed skulls (Figs. 2 and 3) are the following:

Superior orbit (lateral, mid and medial point) Inferior orbit (lateral, mid and medial point) Lateral orbit (superior point and inferior point) Zygomatic bone (superior point and inferior point) Pyriform aperture (inferior point and lateral point)

Temporal bone (upper, mid and anterior point)

All the measurements obtained are expressed in millimeters and are compared with the results obtained by Jensen et al. and Matsuura et al.

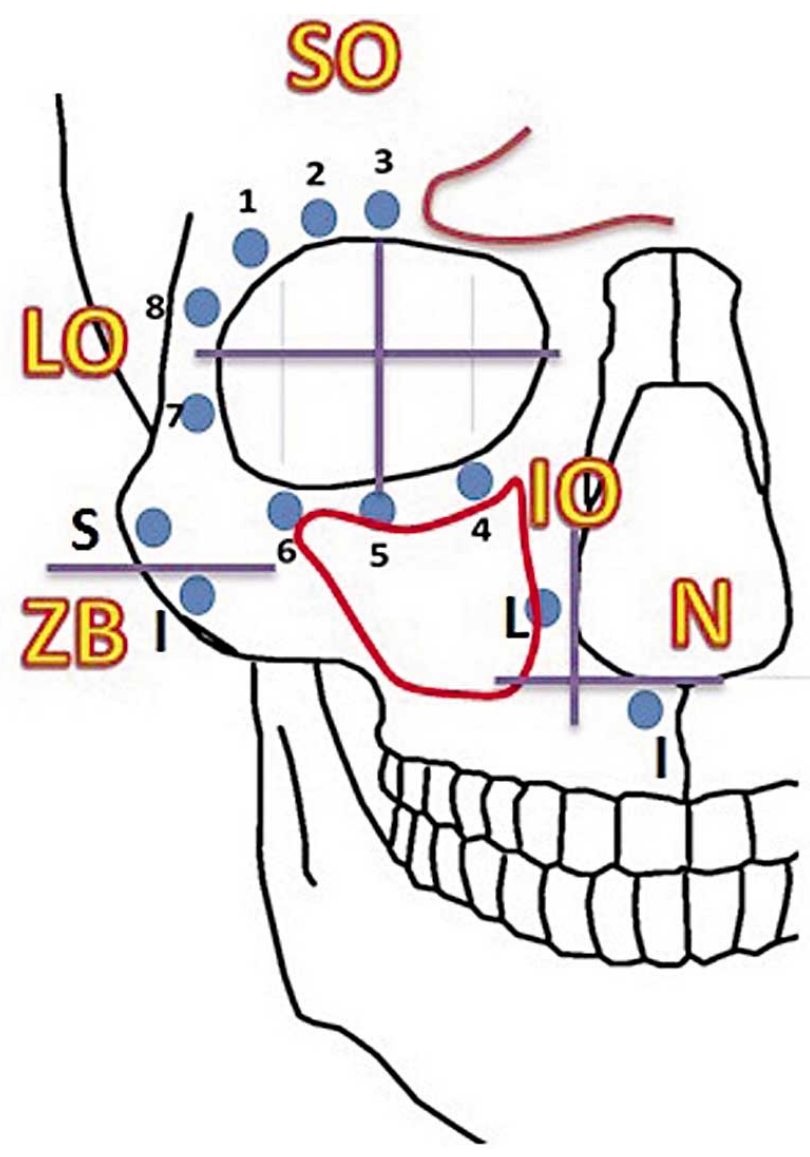

Fig. 1. points selected to take the anteroposterior measurements. The zones of superior orbit (SO), lateral orbit (LO), inferior orbit (IO), zygomatic bone (ZB) and maxilla $(\mathrm{N})$ were determined. The points were determined by numbers and letters $(\mathrm{S}=$ superior, $\mathrm{I}=$ inferior, $\mathrm{L}=$ lateral). 


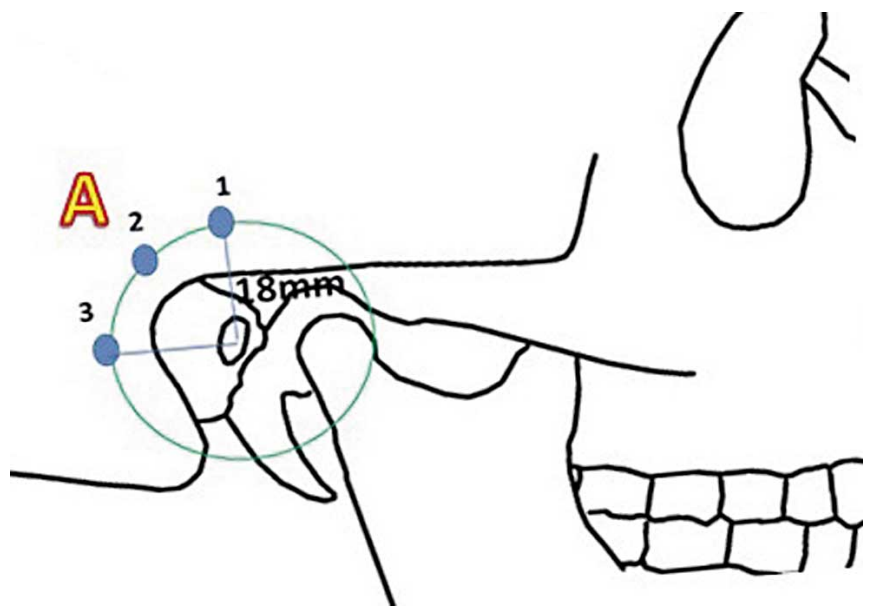

Fig. 2. points selected to take the lateral (transverse) measurements in the area of the temporal bone $(\mathrm{A})$, three points of measurement determined.

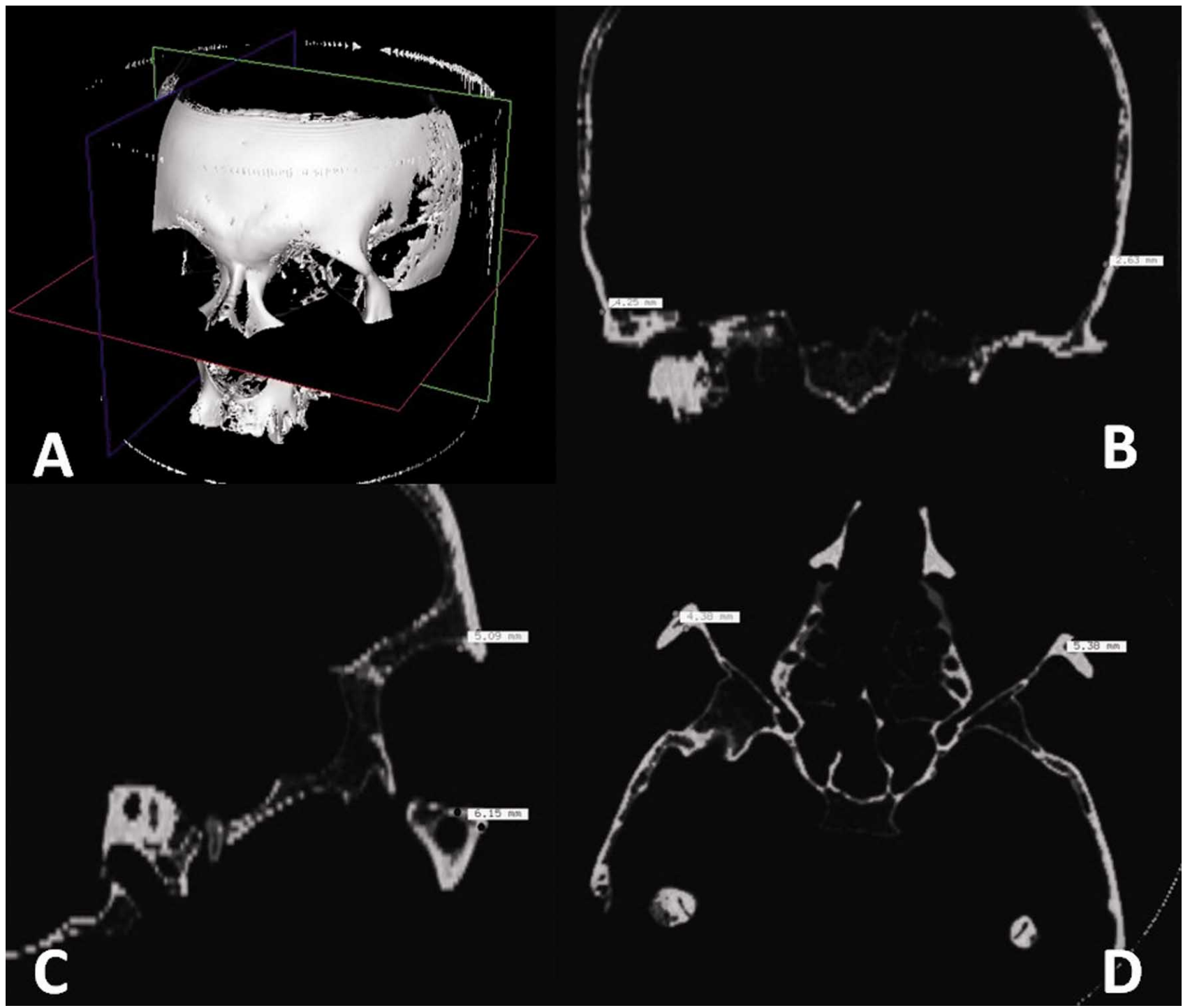

Fig. 3. Cone-beam tomography images. (a) volumetric reconstruction of where the points for analysis were obtained, (b) coronal image where the measurements of the temporal bone were taken, (c) sagittal image where measurements of superior and inferior orbital region were taken, (d) axial image where measurements were taken of the lateral orbit sector and the areas of zygomatic and maxillary bone (nasal). 


\section{RESULTS}

Forty skulls between 20 and 60 years of age were studied; 9 were female and 31 were male; all underwent imaging and study without incident.

Bone width of orbital area. The orbit presented acceptable bone widths. In the superior region the measurements were from $5 \mathrm{~mm}$ lateral to the frontal sinus and in general terms, the width obtained in the frontal bone (superior orbit) was $8.1 \pm 1.9 \mathrm{~mm}$. In the inferior region of the orbit the measurement was taken in three sectors of the anterosuperior part of the maxillary sinus, obtaining an average of $7 \pm 1.7$ $\mathrm{mm}$. The lateral region of the orbit was divided from the frontozygomatic suture with $5 \mathrm{~mm}$ (towards superior and inferior) equidistant from this point, with an average width of $7.9 \pm 1.1 \mathrm{~mm}$ being obtained. These results can be seen in Table I.

Bone width zygomatic body and maxillary bone (perinasal). The measurements obtained at both points of the zygomatic bone indicate an average distance of $11.5 \pm 2.6$ $\mathrm{mm}$; in the inferior region of the pyriform aperture $(5 \mathrm{~mm}$ inferior), the absence of teeth was assumed, obtaining an average of $8.6 \mathrm{~mm}$ in the anteroposterior distance; in the lateral region of the pyriform aperture $(5 \mathrm{~mm})$ a distance of $4.93 \mathrm{~mm}$ was observed (Table II).

Table I. Distribution of the results obtained in the measurements of the orbital region for the male, female group and comparison with the studies by Jensen et al. (1992) and Matsuura et al. (2002).

\begin{tabular}{|c|c|c|c|c|c|c|}
\hline \multirow[t]{2}{*}{ Superior Orbit $(\mathrm{OS})$} & \multicolumn{2}{|c|}{ (1) L ateral (mm) } & \multicolumn{2}{|c|}{ (2) Mid (mm) } & \multicolumn{2}{|c|}{ (3) Medial (mm) } \\
\hline & $X$ & SD or range & $X$ & SD or range & $X$ & SD or range \\
\hline Jensen et al. (1992) & 4.6 & $3.0-6.9$ & - & - & 4.4 & $2.7-7.0$ \\
\hline Matsuura et al. (2002) & 9.9 & 3.3 & 16.0 & 3.1 & 9.5 & 1.9 \\
\hline Male & 7.73 & 1.86 & 8.15 & 1.81 & 9.05 & 2.55 \\
\hline female & 7.14 & 1.33 & 8.53 & 1.8 & 9.52 & 2.18 \\
\hline Total & 7.5 & 1.69 & 8.31 & 1.8 & 9.23 & 2.4 \\
\hline \multirow[t]{2}{*}{ Inferior Orbit (OI) } & \multicolumn{2}{|c|}{ (4) L ateral (mm) } & \multicolumn{2}{|c|}{ (5) Mid (mm) } & \multicolumn{2}{|c|}{ (6) Medial (mm) } \\
\hline & $X$ & SD or range & $X$ & $X$ & SD or & $X$ \\
\hline Jensen et al. (1992) & 5,4 & 2.6-7.1 & - & - & - & - \\
\hline Matsuura et al. (2002) & 11.7 & 3.7 & 6.0 & 2.6 & 4.3 & 2.0 \\
\hline Male & 7.94 & 1.5 & 6.18 & 1.74 & 6.6 & 2.4 \\
\hline female & 7.14 & 1.91 & 6.97 & 2.29 & 5.45 & 2.3 \\
\hline Total & 7.62 & 1.73 & 6.51 & 2 & 6.11 & 2.42 \\
\hline \multirow[t]{2}{*}{ Lateral Orbit $(O L)$} & \multicolumn{2}{|c|}{ (S) Superior (mm) } & \multicolumn{2}{|c|}{ (I) Inferior $(\mathrm{mm})$} & & \\
\hline & $X$ & $\mathrm{ED} / \mathrm{lim}$ & $X$ & $\mathrm{ED} / \mathrm{lim}$ & & \\
\hline Jensen et al. (1992) & 5.9 & $5.6-8.0$ & 6.1 & $4.0-7.2$ & & \\
\hline Matsuura et al. (2002) & 9.2 & 1.4 & 10.0 & 2.6 & & \\
\hline Male & 8.03 & 1.44 & 7.20 & 1.32 & & \\
\hline female & 5.93 & 1.3 & 5.73 & 1.4 & & \\
\hline Total & 7.25 & 1.72 & 6.65 & 1.52 & & \\
\hline
\end{tabular}

Table II. Distribution of the results obtained in the measurements of the region of the body of the zygomatic bone and the inferior and lateral maxilla to the pyriform aperture for the male, female group and comparison with the studies by Jensen et al. (1992) and Matsuura et al. (2002).

\begin{tabular}{|c|c|c|c|c|}
\hline \multirow[t]{2}{*}{ Zygomatic bone (Z) } & \multicolumn{2}{|c|}{ (S) Superior (mm) } & \multicolumn{2}{|c|}{ (I) Inferior (mm) } \\
\hline & $X$ & SD or range & $X$ & SD or range \\
\hline Jensen et al. (1992) & 4.4 & $2.3-6.1$ & - & - \\
\hline Matsuura et al. (2002) & - & - & - & - \\
\hline Male & 11.4 & 2.77 & 9.12 & 2.66 \\
\hline Female & 9.53 & 1.8 & 7.15 & 1.53 \\
\hline Total & 10.7 & 2.6 & 8.34 & 2.46 \\
\hline \multirow[t]{2}{*}{ Pyriform aperture $(N)$} & \multicolumn{2}{|c|}{ (L) Lateral (mm) } & \multicolumn{2}{|c|}{ (I) Inferior $(\mathrm{mm})$} \\
\hline & $X$ & $\mathrm{ED} / \mathrm{lim}$ & $X$ & $\mathrm{ED} / \mathrm{lim}$ \\
\hline Jensen et al. (1992) & - & - & 2.9 & $1.9-3.5$ \\
\hline Matsuura et al. (2002) & - & - & 10.1 & 3.2 \\
\hline Male & 4.73 & 1.48 & 8.14 & 2.28 \\
\hline Female & 3.37 & 1.13 & 6.79 & 2.13 \\
\hline Total & 4.15 & 1.49 & 7.59 & 2.2 \\
\hline
\end{tabular}


Bone width of temporal bone (periauricular). From a point above the anterior part of the external auditory meatus, a circumference with an $18 \mathrm{~mm}$ radius was taken where the superior point was sectioned from where a $90^{\circ}$ angle was made, and this extreme was determined as the inferior point. The midpoint of the measurements was obtained at the bisector $\left(45^{\circ}\right)$. The results for the bone width varied at the different points, with an average value of $3 \pm 6 \mathrm{~mm}$ (Table III).

Table III. Distribution of the results obtained in the measurements of the region of the temporal bone (periauricular area) for the male, female group and comparison with the studies by Jensen et al. (1992) and Matsuura et al. (2002).

\begin{tabular}{lcccccr}
\hline \multirow{1}{*}{ Periauricular $(A)$} & $(1)$ & Superior $(\mathrm{mm})$ & $(2)$ & Mid $(\mathrm{mm})$ & \multicolumn{1}{c}{ (3) } & Posterior $(\mathrm{mm})$ \\
\cline { 2 - 7 } & $X$ & SD or range & $X$ & SD or range & $X$ & SD or range \\
\hline Jensen et al. $(1992)$ & - & - & - & - & - & - \\
Matsuura et al. $(2002)$ & 2.8 & 0.5 & 10.4 & 3.0 & 10.4 & 3.2 \\
Male & 2.96 & 0.7 & 3 & 0.8 & 7.07 & 1.58 \\
Female & 2.95 & 0.86 & 3 & 1 & 7.19 & 1.79 \\
\hline Total & 2.96 & 0.77 & 3 & 0.9 & 7.13 & 1.66 \\
\hline
\end{tabular}

Table IV. Recommended length implant for area, according to the value of minimum bone width obtained in the morphometric study with cone beam TC.

\begin{tabular}{|c|c|c|c|}
\hline \multirow[t]{2}{*}{ Epithesis } & \multirow[t]{2}{*}{ Area } & \multicolumn{2}{|c|}{$\begin{array}{l}\text { Implant length (minor } \\
\text { measurement in landmark) }\end{array}$} \\
\hline & & Male & Female \\
\hline \multirow{8}{*}{$\begin{array}{l}\text { Orbit, eye and } \\
\text { annex structures }\end{array}$} & SO1 & 5.5 & 5.5 \\
\hline & $\mathrm{SO} 2$ & 6.0 & 6.0 \\
\hline & $\mathrm{SO} 3$ & 6.0 & 6.0 \\
\hline & IO4 & 4.0 & 3.0 \\
\hline & IO5 & 4.5 & 4.5 \\
\hline & IO6 & 5.0 & 5.5 \\
\hline & $\mathrm{LO} 7$ & 5.5 & 4.0 \\
\hline & LO8 & 6.0 & 4.5 \\
\hline \multirow{2}{*}{$\begin{array}{l}\text { Major orbit and } \\
\text { /or nose }\end{array}$} & SZB & 81 & $7^{1}$ \\
\hline & IZB & 6.0 & 5.5 \\
\hline \multirow[t]{2}{*}{ Nose } & IN & 5.5 & 4.5 \\
\hline & $\mathrm{LN}$ & 3.0 & 3.02 \\
\hline \multirow[t]{3}{*}{ Ear } & A1 & 3.0 & 3.0 \\
\hline & A2 & 3.0 & 3.03 \\
\hline & A3 & 5.5 & 5.0 \\
\hline
\end{tabular}

1 Conventional implant.

2 Implant may take up to $0.8 \mathrm{~mm}$ total bone width (according to the value of minimum bone width).

3 Implant may take up to $1 \mathrm{~mm}$ total bone width (according to the value of minimum bone width).

\section{DISCUSSION}

Method of evaluation and measurement. The first scientific study designed to evaluate facial bone morphology with the aim of placing implants was by Jensen et al., who used a manual vernier caliper for their measurements. The main disadvantage with this methodology lies in the small movements in the device, which are likely to cause serious discrepancies in the measurement; furthermore, the position of the device can vary from the different curves and angles on a skull. The optimum selection of the measurement points can be altered by the incorrect manipulation of the manual vernier caliper.

Matsuura et al., on the other hand, segmented the skulls they used into different parts with diamond discs and used a digital vernier caliper to take the measurements. This may be a more exact measurement and with fewer variations, but this method destroys the samples, thereby preventing their subsequent use for other educational or research purposes. In this sense, computerized tomography seems to be the most viable and realistic methodology for obtaining exact measurements without altering the samples used (Li et al., 2006; Tsiklakis et al., 2005). In fact, Periago et al. (2008) determined significant differences in the results when they compared the measurements obtained by computerized tomography and with linear devices, whereas de Abreu et al. (2006) reported no differences yet clear advantages of volumetric tomography over other methodologies.

\section{Bone width}

Periorbital region. In this area the lack of an eyeball, orbit and associated tissuesare treated so that the points must be chosen strategically for the installation of craniofacial implants, as in some sectors they are anatomically unworkable (Palmer et al., 2001; Tolman \& Desjardins, 1991). The frontal sinus is one of the biggest anatomical limitations, a structure that tends to increase in size in adults (Fatu et al., 2006). Our results in the superior part of the orbit demonstrated that the extension is adequate for the installation of implants with an average of 23 $\mathrm{mm}$ (from the lateral region of the superior orbit to the edge of the frontal sinus). Our results, in terms of bone width, were slightly smaller than those obtained by Matsuura $e t$ al. and slightly greater than those of Jensen $e t$ al. The lateral part of the orbit is an area adequate for implant placement as it contains 
no significant anatomical structures; the bone width in this sector is approximately $8 \mathrm{~mm}$, which allows implants to be installed without complications; our results were similar to those of Matsuura et al.

The infraorbital rim is a complex area to approach due to the presence of the maxillary sinus. Our results presented widths of approximately 6 to $7 \mathrm{~mm}$, which varies from the results by Matsuura et al., who presented wide variations; these differences can be explained by the different measuring methods and the different angles in the measurement. The medial region of the orbit was not studied because anatomically it is a more complex area and has limitations due to the presence of ethmoidal foramens and limited support bone.

Maxillary / perinasal region. The areas studied demonstrated a suitable bone width; installing implants in the inferior region of the pyriform aperture may be limited by the presence of teeth, in which case the lateral position can be used. The results of Jensen et al. were lower than ours, yet demonstrated an acceptable area with averages of $8.6 \mathrm{~mm}$ in the inferior sector and 4.93 in the lateral sector. Considering the lateral region of the pyriform aperture, it is important to evaluate where the anterior region of the maxillary sinus begins; in our sample it began $7 \pm 0.8 \mathrm{~mm}$ from the edge of the pyriform aperture, granting adequate space for the insertion of implants.

The inferior sector is of questionable use because the presence of teeth can limit the insertion of implants in this sector. Jensen $e t a l$. showed values of $2.9 \mathrm{~mm}$, likely because the measurement was taken at a more anterior point than the one we used ( $5 \mathrm{~mm}$ lateral from the lateral edge of the pyriform aperture). In the inferior region Matsuura et al. presented values over $10 \mathrm{~mm}$ for the installation of implants; in our opinion this value is a result of the point used for the measurement that includes, in the case of Matsuura et al., the alveolar process and extends towards the palatine sector.

The clinical points for the insertion of implants in the perinasal area (Tjellström et al. 1981, 1985; Tjellström; Wolfaardt et al.; Palmer et al.; Pacini et al., 2011) justify the measurements taken in this investigation.

Temporal / Periauricular region. The points selected for the measurement conformed to the clinical proposals of some authors and to record them, a circle with a $18 \mathrm{~mm}$ radius was used that allowed 3 different placement points to be chosen, taking into consideration that only two implants are necessary for an epithesis. Ever since Tjellström inserted the BAHA and the first craniofacial implants in the temporal bone, it has been recognized that this is a viable area for implant placement, although the results of Matsuura et al. showed an average width of $2.8 \mathrm{~mm}$, limiting the installation of this type of implant, the smallest length of which is $3 \mathrm{~mm}$. Nevertheless, few complications have been recounted in the scientific literature, thus demonstrating the efficiency of this technique.

The bone width was increased from superior to inferior, beginning at an average of $2.9 \mathrm{~mm}$ and ending at 6.57 $\mathrm{mm}$, with the places closest to the mastoid process being greatest; in fact, publications have shown the efficiency of this sector despite the pneumatization of the cavities of the mastoid process (Bottini et al., 2008; Gentile et al., 2008a, $2008 \mathrm{~b}$ ). Miles et al. indicated that in narrower areas one probable complication is the exposure of the dura mater, which can also be envisioned in the case of the absence of primary stability of the implant or loss of the implant's osseointegration, which would bring another problem associated with bone repair subsequent to the loss.

Zygomatic bone region. The points for implant insertion proposed by Jensen et al. are in the mid-lateral region of the zygomatic bone and the zygomatic arch; clinically this direction has limited use compared to the anteroposterior or inferosuperior direction in the body of the zygomatic bone (Palmer et al.; Boudard et al., 2001). The body of the zygomatic bone has been used for the installation of different types of implants (Malevez et al., 2004) with good clinical results. In this way, our analysis was conducted in the anteroposterior direction, presenting distances of $12 \mathrm{~mm}$ and $10 \mathrm{~mm}$, which makes it possible to place conventional implants with no major problems.

Finally, we can conclude that there are adequate widths for the safe placement of craniofacial implants; some sectors of the temporal bone are those of less width and could cause complications to the safe installation of these devices. The different anatomical sectors play a fundamental role in the choice of where to implant. If we consider the minimum ranges observed, it is possible to establish the length of specific implants for each area studied in order to avoid the complications associated with excess length and perforation of the second cortical bone.

OLATE, S.; DE MORAES, P. H.; CARIA, P. H. F.; NETTO, H. D. M. C. \& BARBOSA, J. R. A. Morfometría craneofacial para implante craneofacial. Int. J. Morphol., 30(3):1166-1172, 2012.

RESUMEN: Los implantes craneofaciales están siendo cada vez más utilizado para tratar a pacientes con secuelas de resecciones oncológicas, traumatismos, y deficiencias congénitas, entre otras. El objetivo de esta investigación fue establecer las dimensiones óseas mínimas y máximas presentes en los lugares más utilizados para la inserción de implantes craneofaciales. Se diseño un estudio descriptivo que analizó 40 cráneos humanos utilizando cono Tomografía computarizada Cone-Beam; en la reconstrucción volumétrica fueron 
seleccionados los puntos más utilizados en las investigaciones clínicas para la inserción de implantes, que representan la orbital, hueso perinasal, hueso cigomático y regiones periauriculares. La medición de la distancia entre los huesos corticales en los planos sagital, axial y coronal, y las comparaciones entre el sexo y otras investigaciones con el mismo objetivo fueron realizadas. En el área supraorbital, se encontraron valores de 7,92 $\pm 1,82 \mathrm{~mm}$ y en las áreas laterales de 7,54 $\pm 0,98$ $\mathrm{mm}$, lo que permite la colocación de implantes de 5 o $6 \mathrm{~mm}$ de longitud. En el área del hueso cigomático se obtuvieron,dimensiones de 10,4 $\pm 2,35 \mathrm{~mm}$, permitiendo la colocación de los implantes de $8 \mathrm{~mm}$ de longitud. En la región periauricular se obtuvieron valores de $2,93 \pm$ $0,55 \mathrm{~mm}$ en la región superior y $3,1 \pm 0,7 \mathrm{~mm}$ en la región inferior, mientras que en lo zona perinasal se puede colocar implantes de $4 \mathrm{~mm}$ de longitud. Llegamos a la conclusión de que la estructura de los huesos craneomaxilofaciales presenta anchos aceptables para la instalación de implantes; la región periauricular presenta menores dimensiones, con la posibilidad de comunicación intracraneal en zonas sobre el meato auditivo externo.

PALABRAS CLAVE: Implantes craneofaciales; Morfometría ósea; Implante extra-oral.

\section{REFERENCES}

Bottini, D. J.; Gentile, P.; Colicchia, G.; Grimaldi, M.; Trimarco, A. \& Cervelli, V. Alternative techniques in reconstructive surgery: boneanchored extraoral implants for burn cases. Aesthetic Plast. Surg., 32(1):58-62; dicussion 63-5, 2008.

Boudard, P.; Cadre, B.; Herman, D.; Krastinova, D. \& Sabin, P. Pertes de substance facialelocalisées: critères de recours aux implants extraoraux et cascliniques. Rev. Stomatol. Chir. Maxillofac., 102(5):25360, 2001.

de Abreu, A. T.; Veeck, E. B. \& da Costa, N. P. Morphometric methods to evaluate craniofacial growth: study in rabbits. Dentomaxillofac. Radiol., 35(2):83-7, 2006.

Fatu, C.; Puisoru, M.; Rotaru, M. \& Truta, A. M. Morphometric evaluation of the frontal sinus in relation to age. Ann. Anat., 188(3):275-80, 2006.

Gentile, P.; Bottini, D. J.; Colicchia, G. M.; Trimarco, A. \& Cervelli, V. Burns: bone-anchored, extra-oral implantology. J. Burn Care Res., 29(4):627-31, 2008a.

Gentile, P.; Bottini, D. J.; Gravante, G.; Nicoli, F.; Caruso, R. \& Cervelli, V. The use of bone-anchored implants for absent ear. J. Craniofac. Surg., 19(3):744-7, 2008b.

Jensen, O. T.; Brownd, C. \& Blacker, J. Nasofacial prostheses supported by osseointegrated implants. Int. J. Oral Maxillofac. Implants, 7(2):203-11, 1992.

Leonardi, A.; Buonaccorsi, S.; Pellacchia, V.; Moricca, L. M.; Indrizzi, E. \& Fini, G. Maxillofacial prosthetic rehabilitation using extraoral implants. J. Craniofac. Surg., 19:398-405, 2008.

Li, T.; Schreibmann, E.; Yang, Y. \& Xing, L. Motion correction for improved target localization with on-board cone-beam computed tomography. Phys. Med. Biol., 51(2):253-67, 2006.
Malevez, C.; Abarca, M.; Durdu, F. \& Daelemans, P. Clinical outcome of 103 consecutive zygomatic implants: a 6-48 months follow-up study. Clin. Oral Implants Res., 15(1):18-22, 2004.

Matssura, M.; Ohno, K.; Michi, K. \& Egawa, K. Clinicoanatomic study on the craniofacial bones used for cranio- and maxillofacial implants. Int. J. Oral Maxillofac. Implants, 17(1):121-9, 2002.

Miles, B. A.; Sinn, D. P. \& Gion, G. G. Experience with cranial implantbased prosthetic reconstruction. J. Craniofac. Surg., 17(5):889-97, 2006.

Olate, S.; de Moraes, P. H.; Caria, F. P. H.; Vásquez, B. \& Albergaria Barbosa, J. R. Morphometric Study of Orbital Region for Craneofacial Implant Applications. Int. J. Morphol., 29(1):22-6, 2011.

Pacini, R.; Poulain, G.; Bujeaud, C.; Bénateau, H.; Durand, M. \& Durand, M. Epithèses implant-portées: intérêt de la collaboration chirurgienépithésiste. Rev. Stomatol. Chir. Maxillofac., 102(5):270-3, 2001.

Palmer, S.; Brix, M. \& Bénateau, H. Prothèsefacialecomplexe: intérêt des prostheses maxilla-faciales à ancrageosseouxdans le traitement des pertes de substance étendues de la face. Rev. Stomatol. Chir. Maxillofac., 102(5):261-5, 2001.

Periago, D. R.; Scarfe, W. C.; Moshiri, M.; Scheetz, J. P.; Silveira, A. M. \& Farman, A. Linear accuracy and reliability of cone beam CT derived 3-dimensional images constructed using and orthodontic volumetric rendering program. Angle Orthod., 78(3):387-95, 2008.

Tejellström, A. Percutaneous implants in clinical practice. Crit. Rev. Biocompat., 1:205-28, 1985.

Tjellström, A.; Lindström, J.; Hallen, O.; Albrektsson, T. \& Branemark, P. I. Osseointegrated titanium implants in the temporal bone. A clinical study on bone-anchored hearing aids. Am. J. Otol., 2(4):30410, 1981.

Tjellström, A.; Yontchev, E.; Lindström, J. \& Branemark, P. I. Five years' experience with bone-anchored auricular prosthesis. Otolaryngol. Head Neck Surg., 93(3):366-72, 1985.

Tolman, D. E. \& Desjardins, R. P. Extraoral application of osseointegrated implants. J. Oral Maxillofac. Surg., 49(1):33-45, 1991.

Tsiklakis, K.; Donta, C.; Gavala, S.; Karayianni, K.; Kamenopoulou, V. \& Hourdakis, C. J. Dose reduction in maxillofacial imaging using low dose Cone Beam CT. Eur. J. Radiol., 56(3):413-7, 2005.

Wolfaardt, J.; Gehl, G.; Farmand, M. \& Wilkes, G. Indications and methods of care for aspects of Extraoralosseointegration. Int. J. Oral Maxillofac. Surg., 32(2):124-31, 2003.

\section{Correspondence to:}

Prof. Dr. Sergio Olate, DDS, PhD

División de Cirugía Oral \& Maxilofacial

Facultad de Odontología, Universidad de La Frontera

Claro Solar 115, Temuco

CHILE

Email: solate@ufro.cl

Received: 04-04-2012

Accepted: 16-06-2012 